\title{
Construyendo y reconstruyendo identidades y mundos. Propuestas sociales de educación artística con niños indígenas
} Building and Rebuilding Identities and Worlds. Social Artistic Education Proposals with Indigenous Children

\author{
María Fernanda Álvarez Gil \\ Universidad Iberoamericana Ciudad de México, México \\ feralvarezgil@gmail.com
}

\begin{abstract}
RESUMEN
Esta investigación busca demostrar el impacto sociocultural que puede tener la educación artística-visual en los alumnos de $5^{\circ}$ grado de primaria de dos escuelas indígenas en condiciones socioeconómicas vulnerables, una urbana en Chimalhuacán, Estado de México, y la otra rural y bilingüe en la montaña de Guerrero. Por medio de una metodología etnográfica-educativa que incluye representaciones sociales, intervenciones artísticas, entrevistas y cuestionarios, el estudio presenta los resultados que se obtuvieron al implementar con los alumnos de estos contextos, actividades de índole artística encaminadas, por un lado, a generar una conciencia social crítica y transformadora sobre el mundo que los rodea y que les tocó vivir $y$, por otro, conocer, recuperar y fortalecer en ellos su identidad de pueblos originarios. Con estos fines y con base en la corriente teórica del reconstruccionismo pragmático y posmoderno en educación artística, se diseñaron y realizaron con ellos diversos ejercicios creativos que, en un segundo momento, se analizaron e interpretaron para evaluar su trascendencia.
\end{abstract}

Palabras clave: reconstruccionismo pragmático y posmoderno, educación artística, infancias indígenas, representaciones sociales, etnografía educativa

\section{ABSTRACT}

This research seeks to demonstrate the sociocultural impact that artistic-visual education can have on 5th grade primary school students from two indigenous schools in socio-economically vulnerable conditions, one urban in Chimalhuacán, Estado de México, and one rural and bilingual from the mountain of Guerrero. Through an ethnographic-educational methodology that includes social representations, artistic interventions, interviews and questionnaires, the study presents the results that were obtained by implementing with students from these contexts, artistic activities aimed, on the one hand, to generate a critical and transforming social consciousness about the world that surrounds them and they have to live and, on the other, recover and strengthen in them their identity as original peoples. With these aims and based on the theoretical current of pragmatic and postmodern reconstructionism in artistic education, various creative exercises were designed and carried out that, in a second moment, were analyzed and interpreted to evaluate their transcendence.

Key words: pragmatic and postmodern reconstructionism, artistic education, indigenous childhoods, social representations, educational ethnography 
En memoria de mi madre, quien amaba profundamente lo que yo estaba haciendo.

\section{INTRODUCCIÓN}

El objetivo de este estudio es investigar, fundamentar y exponer las posibilidades y alcances de la educación artística-visual para estimular el desarrollo sociocultural de niños indígenas de ámbitos urbanos y rurales socioeconómicamente vulnerables, para despertar en ellos cuestionamientos y conciencia crítica. La indagación abarca dos puntos medulares de este desarrollo social, que son, por un lado, el conocimiento y concientización colaborativos del medio que rodea a los alumnos para proponer y realizar una posible mejora en él $y$, por otro, la reivindicación y valorización de su origen identitario y su vivencia al provenir de o pertenecer a un pueblo originario.

Se trata de conocer y revisar problemáticas actuales tanto de su entorno inmediato como de la sociedad y el mundo que los rodea y del cual forman parte, para buscar, en un momento dado, cambiarlo para bien, así como estudiar la elaboración simbólica e imaginaria de los niños indígenas a partir de la enseñanza artística-visual como reconocimiento y refuerzo de su identidad étnica, social, cultural y su sentido de pertenencia.

El estudio se realizó con un grupo de $5^{\circ}$ grado de una escuela indígena urbana de Chimalhuacán, en el Estado de México, y un segundo grupo del mismo grado en una escuela indígena rural del municipio de Malinaltepec, Guerrero. Se utilizó una metodología etnográfica con doble estudio de casos (cada grupo representa un caso) con instrumentos como intervenciones pedagógicas de índole artística, entrevistas, cuestionarios y el método de las representaciones sociales. La razón de utilizar la etnografía educativa en la búsqueda de desarrollo sociocultural en estudiantes indígenas es que, entre otras cosas, esta metodología cualitativa concibe la educación, el aprendizaje y la investigación educativa como un fenómeno social indisoluble de la experiencia individual y subjetiva (Corenstein, 2001) y permite y da lugar a acciones transformadoras, ya que, como lo explica muy bien Corenstein (2001, p. 12), con esta metodología "se puede, desde la escuela, desde la práctica escolar cotidiana, recuperar el papel activo de los sujetos como constructores de realidades intersubjetivas específicas y como protagonistas capaces de adaptar cada situación a su accionar social cotidiano". 
En concordancia con esto, la investigación se sustentó teóricamente en una visión crítica sobre el racismo y la discriminación en México, relacionados con el origen de pueblo originario, así como en la corriente de educación artística conocida como reconstruccionismo social en sus dos vertientes, la reconstruccionista pragmática y la posmoderna. A través de diversos autores como Dewey (2008), Agirre (2005), Efland, Freedman y Stuhr (2003), estas corrientes educativas proponen, como se verá más adelante, un tipo de educación y aprendizajes basados en el conocimiento y la sensibilización sobre las realidades contextuales de los estudiantes y orientados a generar una concientización y la transformación social que repercutan positivamente tanto en ellos mismos, como en sus relaciones con los otros y con su entorno. Este enfoque etnográfico y reconstruccionista social no concibe escindir el aprendizaje interior y subjetivo del mundo exterior y el contexto sociocultural del estudiante, donde este aprendizaje se constituye y al cual pertenece.

A partir de ello se exponen, analizan, interpretan y comparan los procesos y productos creados por los alumnos para establecer el impacto sociocultural de su aprendizaje y se presentan las conclusiones del trabajo.

\section{METODOLOGÍA}

Partiendo de las principales preguntas de investigación sobre cómo puede la educación artística favorecer la conformación y reafirmación de parte del origen identitario de niños indígenas urbanos y rurales, así como despertar en ellos una conciencia social crítica y transformadora de su entorno y de su mundo, se puede conjeturar, al trabajar directamente in situ con grupos minoritarios y dándoles voz y visibilidad, que el tipo de enfoque metodológico fue en gran parte etnográfico por todo lo que éste implica.

\section{Etnografía educativa}

La etnografía utilizada en el estudio es producto del trabajo de campo realizado en dos escuelas de contextos diferentes, uno indígena urbano y el otro rural, como ya se mencionó, e integra y considera en el ejercicio etnográfico diversas voces y testimonios de la comunidad educativa, como los alumnos, los maestros y los padres de 
familia y cuyos puntos de vista tienen el mismo valor que los de la investigadora (Clifford, 2001). Asimismo, incorpora múltiples instrumentos de recolección de datos considerados, en sí mimos, informantes, como la observación participante, el diario de campo, las entrevistas y cuestionarios, ejercicios de representaciones sociales, así como los mismos productos artísticos realizados.

Basándose en una perspectiva local, pero crítica de lo global y de los sistemas hegemónicos, aquí se trata de un estudio cualitativo (con algunos momentos cuantitativos), que parte del trabajo de campo en microcosmos locales para dirigirse, si esto es posible, a macrocosmos más generales y valoriza la información descriptiva, discursiva, testimonial, plástico-visual, más que las macro cifras o encuestas, a la vez que se sirve de diferentes elementos y propuestas metodológicas tanto para obtener información como para analizarla e interpretarla. El enfoque etnográfico no sólo permite, sino que se caracteriza por una gran flexibilidad en la investigación, pues la metodología y sus instrumentos se van adaptando e implementando muchas veces según lo que va surgiendo en el trabajo de campo.

\section{Intervenciones socioeducativas de carácter artístico}

En el texto llamado Intervención psicopedagógica y currículum escolar de Jesús A. Beltrán y sus colaboradores (Beltrán, Bermejo, Pérez, Prieto, Vence y González, 2000), se revisa el tema de las intervenciones en el aula con gran profundidad, analizando los alcances del potencial aprendizaje significativo que estas estrategias y técnicas de intervención pueden tener en la educación. Hablan de una educación con objetivos, no de acumulación de conocimientos, sino de aprender a aprender; es decir, de utilizar eficazmente el pensamiento.

A nivel sociocultural, que es el que esta indagación busca destacar, las intervenciones artística-educativas en estos contextos de origen indígena con características de pobreza cobran un nivel más que simbólico de voluntad de transformación en el mundo, al incidir directamente en la realidad. Como lo expresa muy bien Villanueva (2005, p. 91), hablando de la acción educativa y retomando a John Dewey y a Paul Ricoeur: 
"Actuar significa ante todo operar un cambio en el mundo" (Ricoeur, 2002). La teoría de la experiencia de Dewey se asume como una teoría de la acción educativa y la teoría del texto de Ricoeur, se asume en tanto teoría de la acción... Cumplir acciones, remite a intervenir intencionalmente en el mundo, con una textura comprensiva, con ciertas intenciones, deseos, motivaciones para y por qué.

Para esta investigación, las intervenciones artístico-educativas se realizaron en las aulas escolares, fueron diseñadas para todos los alumnos y están fundamentadas en la transversalidad, esto es que, a partir de los ejercicios de índole artística, se puede aprender transversalmente una variedad de materias o temas curriculares que no pertenecen necesariamente a la educación artística. Ya que la información y los conocimientos se generan a partir de la experimentación y las vivencias directas del entorno de los niños a través de procedimientos artísticos, la investigación trata de determinar el aprendizaje significativo producido por estas intervenciones a nivel de conciencia, desarrollo y transformación social, así como de sentido identitario y de pertenencia. Los temas seleccionados para realizar las actividades artísticas basadas en la transversalidad partieron del libro de texto de lengua indígena (2011) y del programa de estudios de $5^{\circ}$ grado de 2011, ambos de la SEP, y su elección correspondió a la vinculación que se podía hacer entre las actividades y los contextos de los alumnos, así como con las principales preguntas de investigación referentes al origen indígena, la discriminación y la transformación social por medio del arte.

De esta manera, con los grupos de $5^{\circ}$ grado de la escuela indígena urbana y de la rural, se preparaba la clase, se presentaba el tema respaldándolo con imágenes en una presentación en Power Point, se realizaba la intervención artístico-educativa acordando el tema con el maestro, se fotografiaba el proceso y el resultado, y se socializaban y comentaban con los nińos los resultados. Otro día se presentaba un cuestionario detallado e individual por escrito al grupo en relación con la dimensión social de la actividad realizada. Se redactaba, asimismo, el diario de campo derivado de la observación participante y se hacían entrevistas a los maestros y a algunos padres de familia para una posible triangulación y validación de la información. En 
el trabajo de campo condensado en la escuela de la montaña de Guerrero, se replicaron todas las actividades, pero adaptándolas al contexto y en lapsos de tiempo más cortos e intensivos.

\section{La observación participante}

Como explica Sánchez (2008, p. 104), ya que la observación participante en la etnografía detecta, visualiza y registra fenómenos de interacción social, también da cuenta de la generación y producción de significados y simbolismos entre los actores sociales participantes en dicha interacción: "se pretende captar y comprender las interacciones, las regularidades, las jerarquías, el orden social y sobre todo los significados y sentidos de las prácticas sociales".

De la misma forma, y toda vez que el arte y la educación artística son medios creadores de sentidos, significados y productos simbólicos por antonomasia, lo que éstos generen socialmente durante su proceso de realización y culminación puede representar una parte importante en los análisis e interpretaciones tanto del contexto como de la comunidad estudiada, sus individuos, los procesos y los productos artísticos en sí mismos: "Se trata de captar la complejidad del sujeto como productor de sentidos, así como sus potencialidades de transformación, y no concebirlo sólo como simple reproductor de estructuras y sistemas" (Sánchez, 2008, p. 101).

\section{Entrevistas, cuestionarios y triangulación como controles cruzados}

Las entrevistas se realizaron a los maestros de los cuatro grupos de las dos escuelas, así como a cinco familiares de cada grupo y fueron semiestructuradas; es decir, que se hacen a los informantes determinadas preguntas abiertas, pero si en la información que aportan surgen temas no previstos, pero relevantes para la investigación, se improvisan preguntas en relación con ellos. En este tipo de entrevistas se deja responder libremente a los entrevistados y es por ello que se les llama entrevista a profundidad, porque se ahonda mucho en los temas tratados. Los informantes dan mucha información sobre acontecimientos del pasado o del presente a los que el investigador no puede tener acceso por diferentes razones; asimismo, pueden 
confirmar o contradecir datos de otros informantes o de otros procedimientos de recolección de datos, en un proceso de triangulación o controles cruzados de la información que sirven para dar validez a ésta. La triangulación en estudios cualitativos consiste en comparar y contrastar los datos recabados por diferentes instrumentos, procedimientos o personas para reafirmar o contradecir el conocimiento generado y, de esta forma, dar validez a la información (Denzin, 2015).

Se realizó un cuestionario por escrito a todos los niños de $5^{\circ}$ grado de ambos contextos al final de cada actividad que, para evaluar a los alumnos, abarcaba el desarrollo social entre otros, con preguntas cerradas de opción múltiple o de respuestas varias sobre cada uno de los temas revisados durante el ejercicio artístico.

\section{Representaciones sociales}

Para la cuestión del sentido identitario se utilizó, en parte, la metodología conocida como representaciones sociales, que se adecua muy bien para investigar la noción de construcciones identitarias. Las representaciones sociales intentan conocer y estudiar las ideas e imaginarios que surgen en los grupos humanos sobre cosas, conceptos y fenómenos que se elaboran colectivamente, combinando el conocimiento de sentido común con tradiciones, informaciones, experiencias, medios de comunicación y modelos de pensamiento y educativos. El principal teórico de ellas es el sociólogo francés Moscovici (1979), que parte de las representaciones colectivas de Durkheim pero, contrariamente a éstas, que son representaciones impuestas y coercitivas por las instituciones o grupos sociales, las representaciones sociales de Moscovici (1979) son construcciones grupales que pueden ser aceptadas o no por los miembros del grupo. En el tema aquí estudiado sobre la construcción y sentido de identidad, estas representaciones sociales nos pueden hablar, a través de la educación y la expresión artística, de cómo los niños de estos grupos escolares en una escuela indígena bilingüe urbana y de una rural se perciben a sí mismos en relación con su contexto y su origen sociocultural, y cómo viven esta identidad en su país. En el libro coordinado por Murueta (2004), Alternativas metodológicas para la investigación educativa, Vázquez y Zazueta (2004, p. 89) explican el procedimiento para obtener estas representaciones sociales: 
El camino que se sigue para poder obtener la representación social es tratar de extraer de los sujetos sus conocimientos del sentido común que se constituye a partir de las experiencias espontáneas, pero también de las informaciones que provienen de la tradición, de la educación, de los medios masivos de comunicación, de los contactos sociales en general.

En esta investigación, muchas preguntas de los cuestionarios y entrevistas, en sí mismos, buscaron información sobre las representaciones sociales de los niños y de la población escolar en general, y complementaron las actividades e intervenciones artístico-educativas relacionadas con los aspectos sobre la identidad y la construcción de significados socioculturales.

El criterio para incorporar múltiples instrumentos de recolección de datos como la observación participante, las intervenciones artístico-educativas, las entrevistas, los cuestionarios, las representaciones sociales, fue ecléctico ya que, como explica Rockwell (2009), en el marco de la etnografía educativa, la combinación de técnicas y herramientas de investigación varían según los problemas estudiados y, en este caso, se buscaba que dieran cuenta de los sentires, opiniones, percepciones y subjetividades en general de los actores involucrados y del entorno, principalmente los niños, en relación con las temáticas sociales de la identidad indígena, el arte, la creación y la concientización y transformación para bien del mundo que los rodea. Ya que esta información es de índole subjetiva y cualitativa, la verificabilidad se basa, como ya se mencionó, en la triangulación de la información o controles cruzados, como también se les conoce, que consiste en cotejar dos o más resultados obtenidos con diferentes estrategias o instrumentos metodológicos (por ejemplo observación participante, entrevistas, cuestionarios, diario de campo, etc.) para, de esta manera, verificar y, si es el caso, robustecer las conclusiones de los resultados (Benavides y Gómez-Restrepo, 2005). 


\section{TEORÍAS QUE SUSTENTANEL DESARROLLO \\ SOCIOCULTURAL. MODERNIDAD \\ Y POSMODERNIDAD EN EDUCACIÓN}

\section{Educación, pobreza y multiculturalidad}

La recurrente tensión entre los proyectos culturales y educativos modernos y posmodernos, entre la tendencia a la universalidad, y por lo tanto, a la homogeneización de los primeros y la demanda y exhorto al reconocimiento de pluralidades, minorías y diversidades del segundo, se presenta teóricamente muchas veces como insoluble, cuando en realidad su posible combinación y síntesis podría aportar y recuperar lo mejor de cada propuesta en beneficio de la educación nacional en general, y de los grupos más vulnerables en particular.

En su texto Equidad, diversidad e interculturalidad, Schmelkes (2009) hace una disección muy puntual de las principales causas de la inequidad educativa en nuestros países latinoamericanos, particularmente en México, y explica cómo, por ejemplo, a partir de la modernidad y pretendiendo llegar a una igualdad en la educación, se pensó que el camino era enseñar lo mismo y de la misma manera en todas las escuelas nacionales sin importar el contexto, medio ambiente o saberes previos de los alumnos y partiendo, una vez más, del modelo educativo perteneciente a la cultura dominante, a saber la occidental y principalmente urbana. Esto generó una serie de terribles rezagos, contradicciones e inercias en los grupos más pobres y marginales de nuestro país, que muchas veces coinciden con las poblaciones indígenas y rurales. Al llegar este modelo educativo a estas poblaciones, por lo general, ya es obsoleto en relación con lo que se está enseñando en la ciudad, lo que paraliza cualquier posibilidad de movilidad social, pues el conocimiento generado allí no está actualizado, no es operante, ni se adapta a la realidad de la población, produce desempleo, descalificación o aprendizajes inútiles.

El modelo educativo mexicano surgido de la modernidad, dirigido a atender a la clase media y media baja citadina de las escuelas tradicionales, pretendía y pretende que otras poblaciones de orígenes heterogéneos, como las rurales e indígenas, se adapten a él en procesos homogeneizadores y aculturizantes, bajo la premisa de la 
construcción de una identidad nacional que conduce y condena a estos grupos a perder o a negar su identidad y sus conocimientos originarios, contextuales y ancestrales. La escuela se vuelve, para estas comunidades escolares (padres de familia, maestros y alumnos), la puerta de entrada al mundo "modernizado" y de "progreso" que, supuestamente, mejoraría sus condiciones económicas, pero muchas veces en detrimento de su lengua, su memoria y sus orígenes identitarios. Es importante resaltar las carencias y deficiencias existentes a este respecto en el Sistema Educativo Mexicano, sobre todo en el marco de esta investigación que, como objeto de estudio, busca, en parte, recuperar y fortalecer, por medio de la educación artísticavisual, los orígenes y raíces identitarios de los pueblos originarios de contextos de pobreza.

\section{Lengua originaria, discriminación y racismo}

El bien intencionado, progresista y utópico programa modernista de la educación, aunado a la globalización contemporánea han generado, por su visión del hombre universal, concepciones eurocéntricas y uniformizadoras de la humanidad asociadas al progreso y al desarrollo de los países industrializados, en las que las minorías culturales y étnicas no tienen mucho espacio de representación ni de desenvolvimientos contextuales, identitarios y subjetivos.

En países como México lo anterior se traduce en actitudes, comportamientos y hasta políticas educativas veladamente racistas y discriminatorias, en las cuales las poblaciones marginales, particularmente las indígenas, al diferir de la población mayoritaria, reciben menos recursos tanto materiales como humanos, y aunque sí se registran avances e iniciativas, sus lenguas, cosmogonías, idiosincrasias y cultura en general se encuentran, en los albores del siglo XXI, muy lejos todavía de ser aceptados, valorados y reconocidos como debieran. De nuevo, como plantea Schmelkes (2009, p. 54):

quizá la causa más importante de la inequidad educativa de los pueblos indígenas, se encuentra en el profundo racismo, inconsciente, no reconocido como tal, pero no por ello menos crudo y real, en la cultura de quienes deciden y operan la política en general, y la 
educación, en nuestros países. A los indígenas se les da menos, se les ofrece lo que se cree que necesitan, que siempre es menos que a los demás, se les margina de las decisiones educativas. El racismo se incrusta en las leyes, en los reglamentos, en la forma cotidiana de operar de las instituciones, en las relaciones que se establecen entre blancos o mestizos e indígenas, en las decisiones de quienes tienen en su poder decidir para y por otros. El racismo no concibe que pobreza económica pueda desasociarse de la pobreza cultural. No se concibe alguien pobre económicamente que pueda, como los indígenas, ser rico culturalmente.

En el mismo orden de ideas y corroborando lo que plantea Schmelkes (2009), Moreno (2016), en un muy pertinente y completo análisis de la producción académica actual sobre el racismo en México, disecciona de qué manera, todavía en nuestros días y como secuela de la ideología posrevolucionaria, existe la búsqueda de un supuesto mestizaje nacional. Este mestizaje, que utópicamente pretende negar la existencia de razas para abolir cualquier racismo e igualar condiciones socioeconómicas y culturales, paradójicamente también niega o invisibiliza a los pueblos originarios y poblaciones que quedan fuera de ese imaginario mestizo que, de nuevo, de forma hipotética, presupondría una homogénea y unificada identidad nacional. El racismo, bajo esta perspectiva, no es concebido tanto como una superioridad de razas, sino como lo que afectiva, social y políticamente, en términos de poder y de privilegios, representa la visión del "otro diferente de la mayoría" y que, en realidad, implica procesos y posturas discriminatorios.

En este sentido, desde la perspectiva posmoderna en la línea de la teoría crítica de Giroux (1995) y partiendo de su reivindicación de la diversidad cultural, de lo heterogéneo y plural, la educación aparece como una alternativa convincente y complementaria, es decir, no excluyente, de los propósitos e ideales más democráticos y equitativos del proyecto educativo moderno en México y en otros países multiculturales. 


\section{DOS VERTIENTES DEL RECONSTRUCCIONISMO SOCIAL EN LA EDUCACIÓN ARTÍSTICA}

Por su parte, la corriente reconstruccionista (en sus dos vertientes: el reconstruccionismo pragmático y el reconstruccionismo posmoderno y multicultural) busca reformar la sociedad a través de la educación artística aplicada a la vida cotidiana y a problemas de índole comunitario, socioculturales, de género e identidad, de igualdad y equidad, de minorías y, por supuesto, multi e interculturales diversos (Efland, 2002). Su origen se puede encontrar en varios autores, pero principalmente en las teorías pragmáticas de John Dewey.

\section{JOHN DEWEY Y EL RECONSTRUCCIONISMO PRAGMÁTICO DE LA EDUCACIÓN ARTÍSTICA}

A raíz de la crisis histórica que le tocó vivir después de la gran depresión de 1929, y como consecuencia del sufragismo femenino, del sindicalismo y del populismo rural, el aspecto social de la educación siempre fue uno de los principales intereses de Dewey y al que dedicó muchos estudios. El gran pedagogo norteamericano argumentaba que las escuelas, como tales, no estaban concebidas para una transformación social, sino para reproducir un orden social ya establecido que no promovía una democracia real y más justa. Por lo tanto, lo que él fomentaba era fortalecer y reconstruir valores y sentidos de vida comunitarios en los alumnos, a través de la enseñanzaaprendizaje, tanto teórica como prácticamente, y por medio de la experiencia escolar vivida como colectividad y cooperativismo, para que, a la larga, ellos los adaptaran e implementaran en la sociedad y en el mundo que les tocaría vivir.

Durante unos pocos años Dewey pudo poner en práctica sus principales postulados educativos, que buscaron siempre una aplicación empírica y social del pensamiento a la vida, en relación con la cotidianeidad y la experiencia del estudiante, y sin la cual, según el autor, el conocimiento no se hacía significativo para el niño. Dewey proponía programas escolares en los cuales el alumno pudiera vincular directamente lo aprendido con situaciones de la vida cotidiana y social de su comunidad, y también con circunstancias reales que respondieran a sus propios intereses y actividades. 
Una palabra y concepto clave para entender una parte importante de la visión educativa de Dewey y del reconstruccionismo pragmático es "experiencia”. La experiencia se presenta aquí como el fenómeno de aprendizaje integrador del pensamiento y la vivencia del niño, es decir, del mundo de las ideas con la vida y realidades cotidianas individuales y colectivas surgidas del contexto y que, en última instancia, completado exitosamente, reconstruye el pensamiento y la acción del niño así como el medio social en el que esta integración sucede y se desenvuelve (Efland, 2002).

Dewey investigaba y buscaba también incluir e interrelacionar varias disciplinas en sus investigaciones pedagógicas como ciencias, historia, carpintería, matemáticas, y por supuesto, una muy importante y que es la que aquí se examinará, que es la relativa al arte.

\section{El arte como experiencia integral de la vida}

En El arte como experiencia (Dewey, 2008), Dewey denuncia la separación entre el reino trascendental y elevado donde, hasta ese momento, la teoría había situado al arte (el "gran arte" o "arte o museístico”) y la vida cotidiana de la mayoría de las personas.

Esta visión espiritualista y esotérica del arte trascendentalista y de culto, plantea el autor, no hace más que volver el arte más elitista, apartado de las personas en general y sólo para iniciados, pero, sobre todo, desconectar tanto al sujeto como al objeto de las experiencias concretas del arte que tanto podrían enriquecer su vida en diferentes aspectos.

Una de las funciones primordiales del arte, para Dewey, es generar experiencias estéticas interrelacionadas con otras de la vida cotidiana de todo ser humano, que lo haría más consciente e intensificaría su vivencia ordinaria de las cosas, de su mundo y de sus relaciones con los otros para, en sus propias palabras: "recobrar la continuidad de la experiencia estética con los procesos normales de la vida ... una filosofía del arte es estéril, a menos que nos haga conscientes de la función del arte en relación con otros modos de experiencia” (Dewey, 2008, pp. 11-13). A cualquier edad, en cualquier contexto y para cualquier persona, nos dice el autor, la experiencia del arte, por medio de movimientos dialécticos de tensiones y equilibrios interiores relacionados con los movimientos de la vida 
misma, sus luchas y sus diversas experiencias y procesos, los intensifica y exalta de manera cualitativa para hacerlos más significativos y poderosos en quien los vivencia. La interacción del sujeto con el mundo exterior de los objetos, los acontecimientos y las interrelaciones personales, a través de la experiencia del arte, sea ésta creativa o contemplativa, se enriquece, revitaliza, profundiza, y constituye, asimismo, un aprendizaje en el que la vivencia interior y exterior de la realidad no se puede disociar (Dewey, 2008).

La experiencia artística, a la manera de muchos rituales del pasado que se podrían recuperar, debe relacionarse siempre con diferentes tipos de procesos de la vida para que cobren un sentido y cualidades integrales que enriquezcan interiormente al ser humano e incluye en todo ello, por supuesto, los procesos educativos:

El rito y la ceremonia, así como la leyenda, ligaban lo vivo y lo muerto en una ceremonia común. Eran estéticos, pero más que estéticos... Cada uno de estos modos comunales de actividad unía lo práctico, lo social y lo educativo en un todo integral con forma estética. Introducían los valores sociales en la experiencia de la manera más impresionante. Conectaban las cosas francamente importantes y francamente hechas con la vida sustancial de la comunidad (Dewey, 2008, p. 371).

\section{La enseñanza y la experiencia del arte como reconstrucción social}

De esta forma, las características del fenómeno de lo artístico y las diferentes experiencias vitales que éstas despiertan, interrelacionan e intensifican la vida misma y su percepción, originando derivaciones importantes en los ámbitos sociales y educativos aquí revisados, que tienen que ver con las implicaciones de las experiencias tanto artísticas (relativas a la creación), como estéticas (relativas a la contemplación) en procesos pertenecientes a estos ámbitos.

En estos espacios educativos y a través de proyectos de creación artística comunes, cuya temática puede abordar problemáticas relacionadas con su comunidad, los alumnos involucrados se comprometen socialmente con los otros en dos niveles: al trabajar el proyecto en equipo desarrollando tolerancia, consenso, respeto, diálogo, 
colaboración y al reflexionar consciente y críticamente y proponer soluciones, en la actividad, a problemáticas colectivas.

Esta preocupación de la corriente reconstruccionista pragmática por interrelacionar las experiencias artísticas con experiencias de otros dominios de lo común y cotidiano; por tomar consciencia de las mismas y lograr con ellas intensificar la vida; por cohesionar tanto en los procesos como en las temáticas y las formas de trabajo a grupos sociales y proyectos colectivos para buscar, en identificaciones sensibles, transformar para mejorar la vida propia y comunitaria, desembocaría, una vez acabadas las utopías modernas, en el reconstruccionismo posmoderno y multicultural.

\section{EL RECONSTRUCCIONISMO POSMODERNO Y MULTICULTURAL DE LA EDUCACIÓN ARTÍSTICA}

Si el reconstruccionismo pragmático en la educación del arte, representado principalmente por John Dewey, surgió como una preocupación sociocultural de un país con fuertes problemas económicos y sociales en una época todavía moderna, su continuidad aparece como el resultado de una educación artística producto de un cambio cultural de paradigma mundial entre modernidad y posmodernidad.

Con los cuestionamientos a la razón como panacea universal, las migraciones y movilidades humanas, los cambios sociopolíticos en el mundo y la revolución cibernética, entre otros factores, las configuraciones sociales se han ido modificando, se han generado sociedades híbridas y plurales que no pueden ser explicadas ni educadas desde un sólo modelo humano occidental e individualista. Las propuestas y los sistemas educativos cambiaron también, muchos de ellos derivados y transformados por las apuestas y los logros anteriores, como es el caso del reconstruccionismo posmoderno y multicultural, producto del pragmatismo de Dewey recién revisado aquí.

Son muchas y muy variadas las características que conforman y definen el reconstruccionismo posmoderno y multicultural. A continuación se hablará de las más importantes, que están, sobre todo, relacionadas con esta investigación.

La educación artística en la época posmoderna no considera el fenómeno artístico-visual como una disciplina autorreflexiva y cerrada en sí misma. Por el contrario, parte de la idea de que es un fenó- 
meno que forma parte de un sistema cultural como un todo social, en el cual la cultura y las representaciones visuales se relacionan con otros símbolos provenientes de diferentes disciplinas, que responden a múltiples prácticas sociales con contenidos o significados diversos ligados a estas prácticas (Agirre, 2005). Si bien el modernismo había compartimentado y separado las disciplinas científicas de las humanísticas y artísticas, presentándolas como opuestas y priorizando muchas veces la ciencia, el reconstruccionismo posmoderno, con cuestionamientos a los sofisticados campos de exterminio, como Auschwitz, o las bombas nucleares y otras atrocidades producto del progreso y avance científico, destaca la importancia de las disciplinas artístico-humanísticas para mediar en el abuso y mal uso de ciencia y tecnología, que pueden ocurrir sin una ética adecuada y un espíritu crítico, producto de pensamientos más humanistas (Efland, Freedman, Stuhr, 2003).

Por otro lado, y toda vez que esta corriente educativa está tan centrada en las configuraciones y alcances sociales del arte y su enseñanza-aprendizaje, los contextos aquí determinan una parte muy importante en el transcurrir del proceso educativo a nivel de temática, de producción y de análisis, pues la investigación práctica se desarrolla en contextos etnográficos y socioeconómicos muy específicos. Dicen Efland, Freedman y Stuhr (2003, p. 73): "la razón fundamental de enseñar arte es preparar a los estudiantes a comprender los mundos sociales y culturales en los que ellos habitan. Esos mundos son representaciones creadas con las cualidades estéticas de los media".

De esta manera, el reconstruccionismo posmoderno en educación artística adquiere un cariz sociopolítico importante, como mucho del arte contemporáneo, desde el momento en que considera esta educación una cultura visual. En ella intervienen la creación, la interpretación y la crítica del medio social, así como de las representaciones sociales de los grupos humanos y la cultura mediática a través de la producción artística con intenciones de comprenderlos, transformarlos y mejorarlos, es decir, reconstruirlos socialmente por medio de la toma de conciencia y de la sensibilización que estas actividades artísticas despiertan y promueven (Agirre, 2005).

Dentro del reconstruccionismo posmoderno aparece, a nivel mundial, una vertiente multicultural que para esta investigación es 
sumamente relevante, pues los sujetos de estudio y los participantes son principalmente niños de origen indígena en un país multicultural, como México.

Con las grandes movilizaciones geográficas del ser humano a lo largo de su historia, incrementadas en las últimas décadas por cuestiones bélicas, sociopolíticas o económicas, las configuraciones sociales en el mundo se han modificado, y han dado lugar a sociedades cultural y étnicamente variadas. Aunado a ello, los espacios ganados por los derechos de la mujer, la cada vez mayor consideración de todo tipo de minorías (étnicas, religiosas, de capacidades diferentes, de preferencias sexuales, de minusvalía) conforman, en su conjunto, sociedades multiculturales y diversas en las que ya no cabe un único discurso hegemónico que explique las realidades humanas y sociales. Esto ha generado grandes preguntas, debates y propuestas sobre la inter y la multiculturalidad a nivel teórico y académico, político y social; todo ello es una de las características de la posmodernidad.

En educación artística, la multi e interculturalidad se muestra en problemáticas y temáticas de opresión y desigualdades socioeconómicas, cuestiones de género y diversidad sexual, problemas raciales que, por medio de reflexiones y creaciones de orden artístico, intervienen para transformar conciencias, sensibilidades y relaciones sociales (Efland, Freedman, Stuhr, 2005). Todo ello está inevitablemente relacionado con los contextos socioculturales de los alumnos de esta investigación, y en función de éstos se implementaron las actividades, como se verá más adelante en los ejemplos.

Todo este cuestionamiento que la corriente posmoderna ha hecho a la modernidad y sus grandes discursos universalistas, absolutistas y dogmáticos (pero también, hay que decirlo, igualitarios) han abierto espacios cada vez más visibles para recuperar lo que Lyotard (2006) ha llamado pequeños relatos o narrativas, y que en etnografía educativa coinciden muchas veces con los contextos y conocimientos locales de Clifford Geertz (1994). Estos pequeños relatos reivindican y dan voz a estos grupos minoritarios que, hasta ahora, no la han tenido, buscando hacerlos partícipes y creadores de su propia historia (Freire, 2002). Junto con la etnografía educativa, el reconstruccionismo posmoderno en educación artística sustenta, promueve y propone, tanto teórica como prácticamente, la producción de estos pequeños relatos. 
Una de las cuestiones que se juegan en la elaboración de las pequeñas historias minoritarias y de la creación artística en general es la construcción de la identidad, entendida aquí no como algo establecido a priori, sino como un fenómeno dinámico interno y externo que se modifica conforme maduramos, tomamos conciencia, nos conocemos a nosotros mismos, interrelacionamos y nos transformamos (Agirre, 2005). Para grupos minoritarios, particularmente niños de origen indígena en situaciones socioeconómicamente vulnerables, con quienes esta investigación ha trabajado la educación artística, esta recuperación y reconstrucción identitaria individual y colectiva reivindica su autoestima, su propia historia y la de su contexto ayer y hoy, y los hace conscientes de ella en un mecanismo muy freiriano que busca contribuir así, a partir de lo que se podría llamar una alfabetización de la cultura visual, a seguir imaginando, construyendo y reconstruyendo también su presente y su futuro. En un mundo cada vez más globalizado, cuyas tendencias modernas de uniformización humana no han disminuido, rescatar y preservar identidades minoritarias que, como las indígenas, pueden hasta perderse o desaparecer, es hoy una necesidad imperiosa y muy pertinente.

\section{Aspectos de desarrollo social surgidos de las corrientes reconstruccionistas en la educación artística y la evaluación del aprendizaje}

A partir de las teorías, parámetros y aspectos socioculturales e identitarios que se acaban de revisar en la etnografía educativa y las corrientes de educación artística reconstruccionista pragmática y posmoderna, se establecen los siguientes criterios de análisis del desarrollo social que se buscó observar, implementar y evaluar en los alumnos, por medio de las intervenciones artísticas en el aula y de los instrumentos metodológicos complementarios:

- Crítica, transformación social y de su medio.

- Intercambio de experiencias.

- Conciencia social, ética y de valores.

- Conocimiento y entendimiento de su contexto, de su origen y de su identidad. 
- Convivencia e interacción entre pares y comunitarios.

- Trabajo en equipo y colaboración.

Cabe aclarar aquí que, para evaluar si en el proceso de realización de las diferentes actividades, los estudiantes lograron cumplir con el aprendizaje y asimilación de estos criterios de desarrollo, el estudio se basó en análisis cualitativos como los concibe Eisner (2004), expuestos en su libro El arte y la creación de la mente, donde los criterios no son medibles sino valorativos. El autor explica cómo en materias humanísticas y sociales, pero sobre todo artísticas, la evaluación del aprendizaje de los alumnos tiene que ser flexible y abierta para demostrar, desde ellos mismos, sus procesos, experiencias, contextos y puntos de vista; es decir, expresar desde su subjetividad lo que han aprendido, por medio de instrumentos o artefactos que den cuenta de sus mismas creaciones artísticas, apreciaciones, pensamientos, percepciones y palabras. Para Eisner (2004), las pruebas o evaluaciones de aprendizaje estandarizadas reflejan artificialmente lo que el alumno aprendió en concreto para la prueba escolarizada y lo que sabe hacer, pero no lo que hará en la realidad para llevar una vida satisfactoria y socialmente constructiva, que es lo que él considera verdaderamente relevante. En tal sentido, en este estudio se ha utilizado la evaluación cualitativa de los aprendizajes que generó la educación de arte ya que, como lo explica el autor, la evaluación de las creaciones artísticas de los alumnos no necesariamente tiene que responder a cuestiones de arte, sino que pueden estar relacionadas, como en este caso, con enseńanzas, actitudes, sensibilizaciones y conocimientos de tipo psicosocial:

El enseñante de arte tiene muchas opciones para evaluar el trabajo de sus alumnos, pero entre éstas se encuentran aspectos del desarrollo de los estudiantes que pueden tener muy poca relación directa con las artes. Puede que el alumno necesite tener más confianza en sí mismo, tener más oportunidades de asumir responsabilidades o atreverse a intentar cosas nuevas. Al realizar una evaluación el enseñante puede dar prioridad a estas opciones porque, a la larga, y desde el punto de vista de los objetivos generales de la educación, estas opciones podrían tener preferencia (Eisner, 2004, p. 224). 


\section{PUESTA EN USO}

\section{Referentes contextuales de las escuelas}

Si bien los contextos de las escuelas donde se realizó la investigación tienen puntos en común, como la población de origen indígena y un nivel socioeconómico de alta vulnerabilidad, existen, asimismo, varias diferencias entre ellas y sus comunidades educativas, que repercutieron de manera importante tanto en las creaciones como en los desempeńos de los trabajos realizados, en las interpretaciones y análisis de los resultados, así como en las experiencias, visiones y actitudes de los participantes involucrados.

La escuela urbana de Chimalhuacán, Estado de México, está situada en una zona de migrantes de diferentes lugares de la República, que se mudaron allí buscando mejores condiciones de trabajo y de vida; se caracteriza por tener en su alumnado un mosaico diverso de orígenes étnicos y son migrantes de primera o segunda generación, por lo que la raíz de pueblo originario se ha ido diluyendo, ya sea por rechazo o negación de éste o, simplemente, por adaptación e integración a un medio en que este origen sociocultural no predomina, es francamente rechazado o discriminado (Schmelkes, 2009; Moreno, 2016). Los alumnos hablan, en su mayoría, español y muy pocos, alguna lengua originaria.

Por su parte, la escuela bilingüe rural de la montańa de Guerrero es más homogénea en su población, pues todos los alumnos y la mayoría de los profesores son de la etnia méphaa o tlapaneca, y también en su mayoría hablan la lengua del mismo nombre. Este origen común y el hecho de hablar todos o casi todos los alumnos el mismo idioma, cohesiona a la vez que fortalece su sentido identitario de pueblo originario, del cual, en general, están muy orgullosos $\mathrm{y}$ viven con total naturalidad.

\section{Árbol genealógico}

A partir del libro de texto de lengua indígena de la SEP (2011, p. 63), con los objetivos de investigar sobre la historia familiar y de sus seres queridos, comprender la importancia de los lazos de parentes- 
co o más cercanos en la vida social de la comunidad y reflexionar sobre la importancia de estos lazos para enteder quiénes somos, se presentó a los alumnos un Power Point explicándoles qué es un árbol genealógico y quiénes, normalmente, lo componen, de qué se trata el arte-objeto y la instalación artística, así como ejemplos de autorretratos y retratos pintados por artistas mexicanos de diferentes épocas. A partir de ello, los alumnos de ambas localidades realizaron un árbol genealógico representando autorretratos y retratos de los parientes más cercanos, con diversas técnicas de expresión plástica como crayones de cera, plumines, scratch y pintura acrílica. Al final, junto con algún familiar que los acompañó y ayudó, montaron un árbol genealógico con ramas, una cubeta o bote, yeso, tierra o cemento. Plantaban, por así decir, la rama principal donde situaban el autorretrato y la imagen de los hermanos, e iban agregando los retratos de sus padres, abuelos maternos y paternos o personas importantes en las ramas que se bifurcaban (véase la figura 1).

Figura 1: Árboles genealógicos
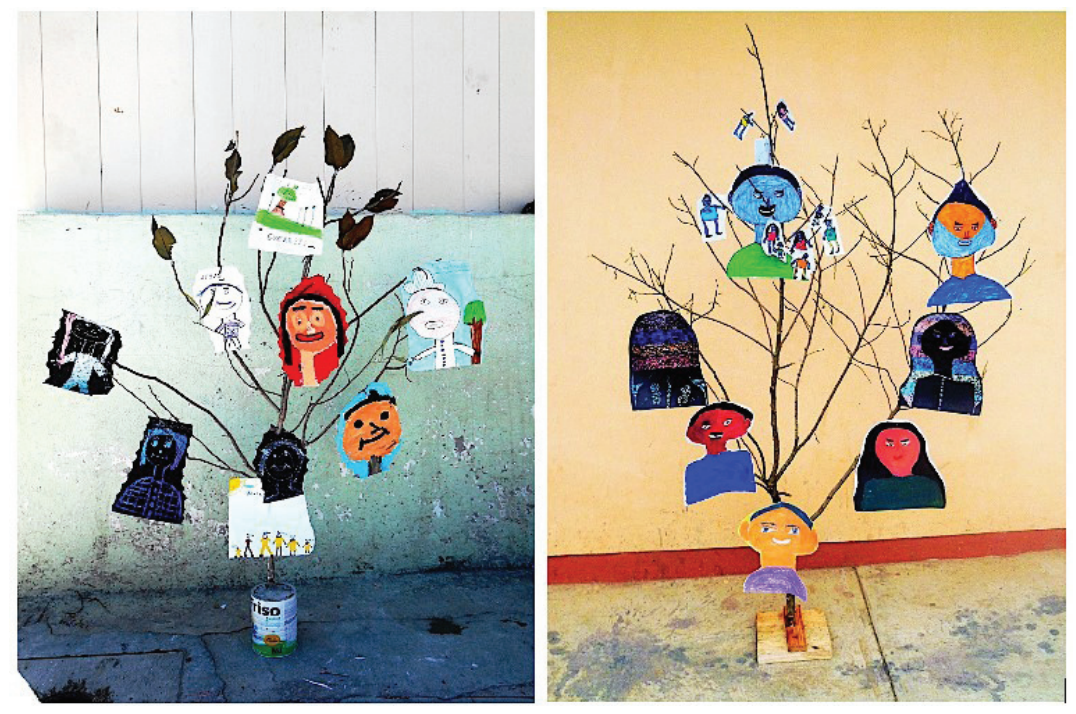

En el cuestionario realizado después de la actividad, con preguntas cerradas de opción múltiple, se pudo observar que a $55.5 \%$ de los alumnos de Chimalhuacán y a 59\% de los de Guerrero represen- 
tarse en un autorretrato y realizar el árbol los hizo pensar sobre quiénes son y, para la mayoría de ellos, esto fue agradable. Asimismo, en Chimalhuacán, 62\% de los niños reflexionaron sobre sus origenes y de dónde provienen, mientras en Guerrero este porcentaje fue sólo de 36\%. En este mismo orden de ideas, para más de $70 \%$ de los niños de Chimalhuacán, esta actividad los condujo a preguntarse sobre el lugar de origen de los padres, mientras que para los niños de Guerrero, este porcentaje fue más bajo, sólo 36\%. Respecto a esto último, resulta pertinente comentar aquí que, de nuevo respondiendo a la validación de la información por triangulación, según comentarios y puntos de vista tanto de maestros como de padres de familia, para los niños del contexto urbano del Estado de México, el hecho de que sus familiares o ellos mismos hayan migrado es un asunto significativo y ha determinado ciertos aspectos de su vida e historia personal, como dejar al resto de su familia en el pueblo, cambiar de entorno, buscar otras condiciones de vida, estar muchas veces separados de alguno de los progenitores, etc. En cambio, los niños de la montaña de Guerrero, en su mayoría, no han tenido estas experiencias y es muy posible que por eso la actividad del árbol genealógico no les haya despertado demasiados cuestionamientos sobre su lugar de origen e historia y los de sus familias.

Por otro lado, aunque relacionado con lo anterior, en las preguntas tocantes al refuerzo de vinculos familiares a través del ejercicio, $60 \%$ de niños de $5^{\circ}$ grado de ambas escuelas sintió que, pintar a su madre, los había acercado, mientras que a entre $45 \%$ y $65 \%$ los había acercado al padre. También resulta relevante que en Chimalhuacán, a la pregunta con varias opciones de respuesta sobre lo que más les había gustado de hacer el árbol, 85\% de los niños haya respondido que fue el trabajar junto con los miembros de su familia. De acuerdo con lo expresado por el maestro de ese grupo, muchos de sus alumnos viven una gran ausencia de los padres, bien sea porque están trabajando la mayor parte del día y casi no los ven, bien porque viven en los Estados Unidos. Esto podría explicar, en parte, la importancia que asignaron a pintarlos o a armar, junto con alguno de ellos, el árbol genealógico. Reforzando estos datos, en un primer momento, cuando los niños representaron a sus padres en la escuela urbana, les hice a algunos de ellos una breve entrevista sobre 
lo que habían sentido al pintarlos, y las palabras que más a menudo surgieron en la grabación fueron, en este orden: "amor, alegría, emoción, separados, cariño, inspirado, expresado, contenta”.

Dentro de la misma temática de los orígenes y como complemento a la actividad del árbol, los estudiantes de Chimalhuacán hicieron, junto con los padres, algún otro familiar o persona cercana, un mapa del estado de donde provienen, relacionándolo con características de la localidad, entre las cuales se encuentra el origen indígena, la flora y fauna, la gastronomía, las fiestas y costumbres, los paisajes, al mismo tiempo que les platicaban a los niños sobre ese lugar o comunidad de origen (véase la figura 2). La actividad se vinculó al tema de la migración, perteneciente a la materia de Geografía del programa de estudios de $5^{\circ}$ grado de 2009 de la SEP (2010, p. 184) y con el tema de las características y aportes de los diferentes grupos culturales del país de la materia de Formación cívica y ética, asuntos que se vinculan muy oportuna y acertadamente con la realidad de estos niños.

- Figura 2: Mapas del estado de origen
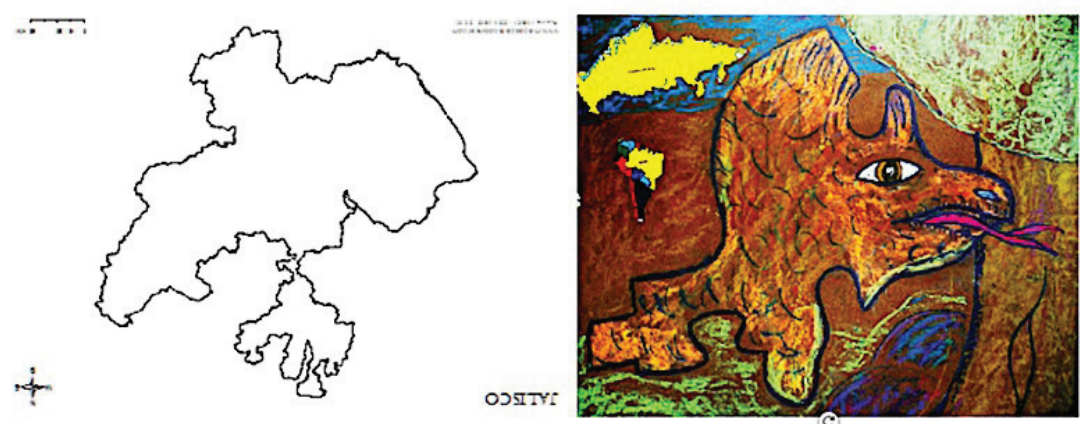

oวsт:
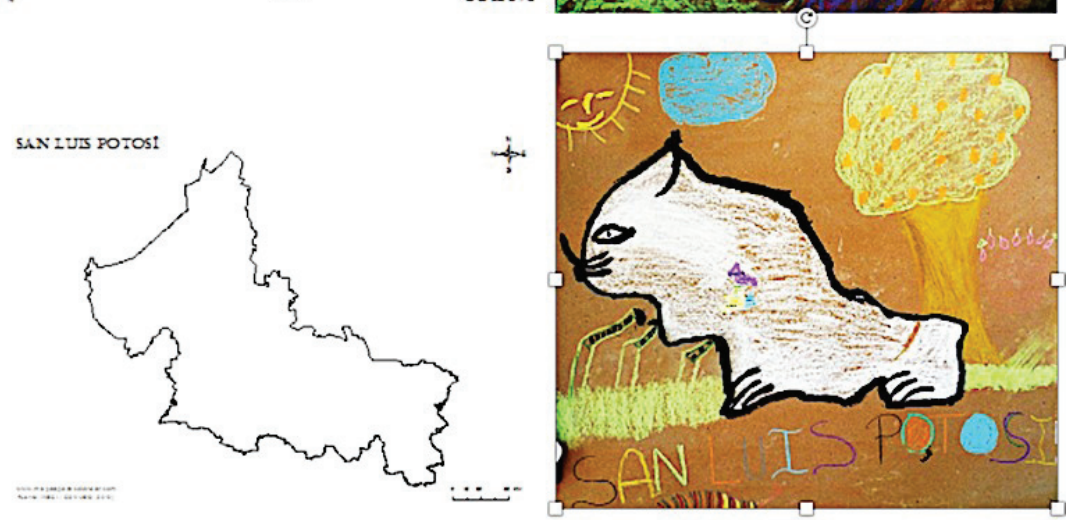


\section{Mapas del estado originario}

Se presentó a los alumnos y sus familiares un Power Point con imágenes de arte, mapas y cartología para la explicación del trabajo y la estimulación creativa. El ejercicio condujo a los alumnos a conocer y a valorar mejor sus orígenes, el de sus padres, y por lo tanto, a reflexionar sobre ellos mismos, de dónde vienen, quiénes son y cómo se identifican con sus compañeros de clase en este origen común. Además, propició acercamientos y convivencias familiares al trabajar junto con los padres o parientes.

La escuela de Chimalhuacán fue fundada para niños indígenas migrantes y sus familias, en una zona conurbada cuya población proviene básicamente de otros estados de la República; por ello la actividad tuvo mucho eco y repercusión en la comunidad educativa del $5^{\circ}$ grado urbano. Por ejemplo, para 75\% de los alumnos, saber acerca del lugar de origen de sus familiares les hizo pensar que una parte de ellos proviene también de allí, y 90\% de entre ellos, que no lo han hecho, quisieran conocer ese lugar. Asimismo, a 78.5\% de los niños les gustó saber que uno de sus progenitores es indígena y $86 \%$ sintió que conocieron mejor a sus compañeros al compartir su origen.

Por su parte, el testimonio de una madre del grupo de $5^{\circ}$ de Chimalhuacán, al preguntarle sobre su propia experiencia y la cercanía y la curiosidad que generaron en su hijo los trabajos, parece confirmar, triangulando de nuevo la información, todos estos datos surgidos de ambos ejercicios y cuestionarios sobre el árbol genealógico y el mapa, así como su impacto:

Nos acercó porque, como te digo, me preguntaba que cómo era su papá, si sí conocía bien a su papá, a sus abuelitos en una plática que tuvimos como de madre e hijo sobre la migración, que fue el otro tema y que se relacionó con el del árbol genealógico. Entonces, sí me hacía preguntas y nos tuvo unidos. Yo sentí muy bonito, sí me emocioné, a mí sí en realidad me gustan todos sus trabajos y me gustan que les hagan todas esas actividades a los niños. Yo me sentí muy bien, muy a gusto, la verdad sí me gusta trabajar con él, pues una también se expresa. 


\section{Reivindicación inter y multicultural y contra la discriminación}

Como se explicó en el apartado metodológico, se utilizó en la investigación la alternativa metodológica de las representaciones sociales para sondear e indagar aspectos de identidad, autopercepción y construcciones sociales de los alumnos, lo que refleja cómo piensan y sienten acerca de ellos mismos, así como de la comunidad educativa en general, compuesta por padres, maestros y alumnos. A ello se suma lo visto en televisión o internet, lo escuchado en el radio o en la calle, las costumbres y tradiciones de su contexto, que determinan la percepción y sentir del grupo acerca de ciertos temas y lo que socialmente significan. Con esta idea, se realizaron dos actividades que se presentarán a continuación, para extraer de ellas información sobre los asuntos del racismo, las minorías socioculturales, la discriminación y el origen indígena en nuestro país, y a partir de ello, promover reflexiones, discusiones, concientizaciones y actitudes positivas al respecto en los alumnos, que las actividades, ya en sí mismas, por su carácter socializante y colaborativo, fomentan.

\section{Móvil de los colores humanos}

El móvil está formado por cuatro o cinco máscaras de diferentes colores. Los alumnos trabajaron el tema del color de la piel, las zonas donde geográficamente se ubican mayoritariamente los diferentes colores y por qué varía. Se les mostró de nuevo un Power Point donde se les explicó que la piel cambió a lo largo del tiempo por las diferencias climáticas y sobre el pigmento de la melanina, su función en el cuerpo humano y su causa científica, así como el origen común de la especie humana en África. Se les habló sobre cómo hacer las máscaras y trabajaron en tres sesiones: en la primera la recortaron y le pusieron el papel de baño con pegamento blanco diluido; en la segunda, ya seco lo anterior, pintaron y decoraron la máscara y la barnizaron (véase la figura 3) y en la tercera, realizaron en equipos los móviles con las máscaras de los diferentes colores (véase la figura 4). 

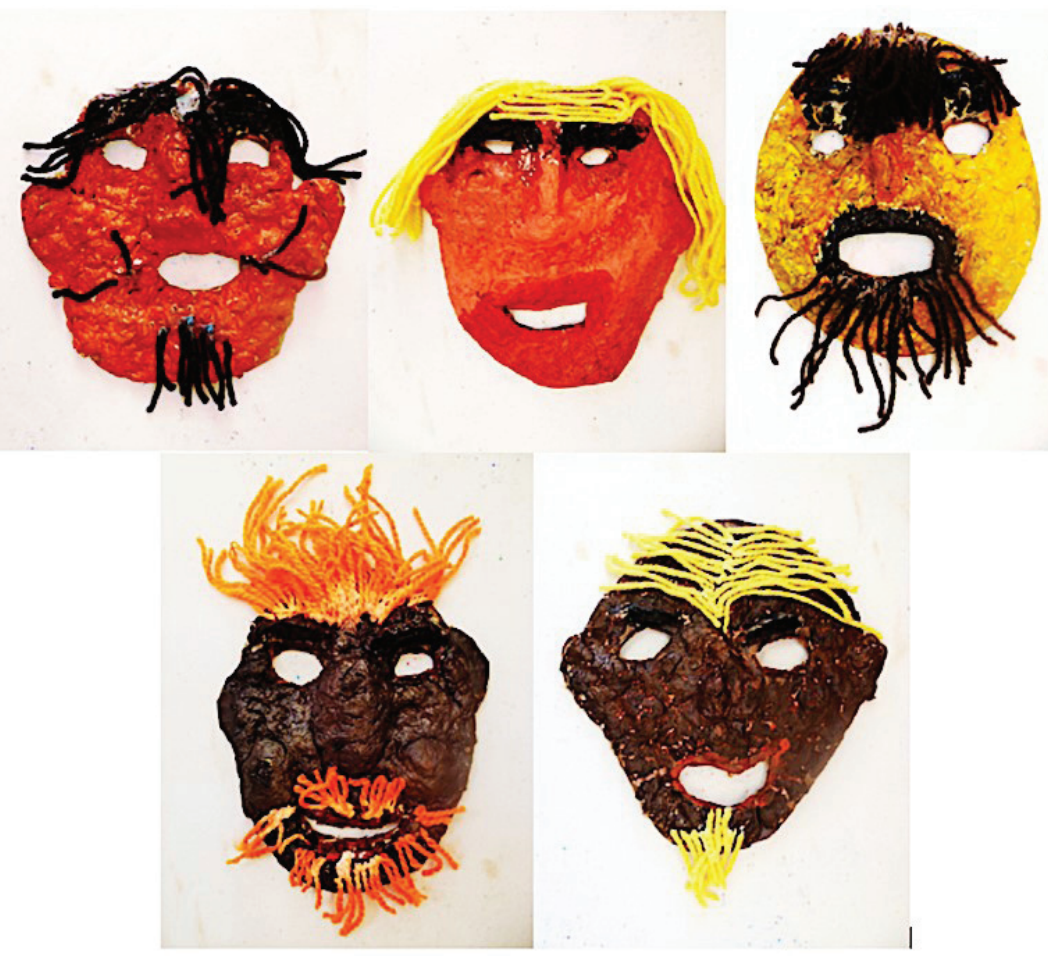

En Chimalhuacán, de acuerdo con lo arrojado en diferentes preguntas cerradas y de opción múltiple, 10 alumnos de los 30 que conformaban el grupo, es decir, casi $35 \%$, quisieran tener otro color de piel y entre esos 10, el $40 \%$ representado por 4 de ellos, piensa que a alguien le va bien o no en la vida según sea su color de piel; 30\% piensa que su color es feo o se avergüenzan de él, mientras otro $30 \%$ preferiría tener otro color, porque creen que así es la gente en otros países.

Las razones que esgrimen los 10 niños $(33.3 \%)$ que quisieran tener otro color de piel tienen que ver con discriminación relacionada con el origen, la población originaria a la que pertenecen y hasta con la misma nacionalidad (y el hecho de pertenecer a otro país) que, dentro de sus representaciones sociales, asocian con éxito, belleza y orgullo, o con fracaso, fealdad y vergüenza, según lo que dicen los resultados de los cuestionarios, pero también de acuerdo con lo que varios de los maestros comentaron en las entrevistas, res- 
pondiendo así a la validación que el método de la triangulación, en este caso de personas, da a estos datos.

De nuevo, estas cifras dicen mucho sobre el pensar y el sentir de los alumnos de este grupo, pero que reflejan los de la comunidad, sobre la percepción y apreciación de lo que en nuestra sociedad significa pertenecer a determinados grupos humanos, que muchas veces se distinguen, entre otras cosas, por un cierto color de piel o rasgos como lo son el grupo indígena o poblaciones originarias.

Figura 4: Móvil de los colores humanos

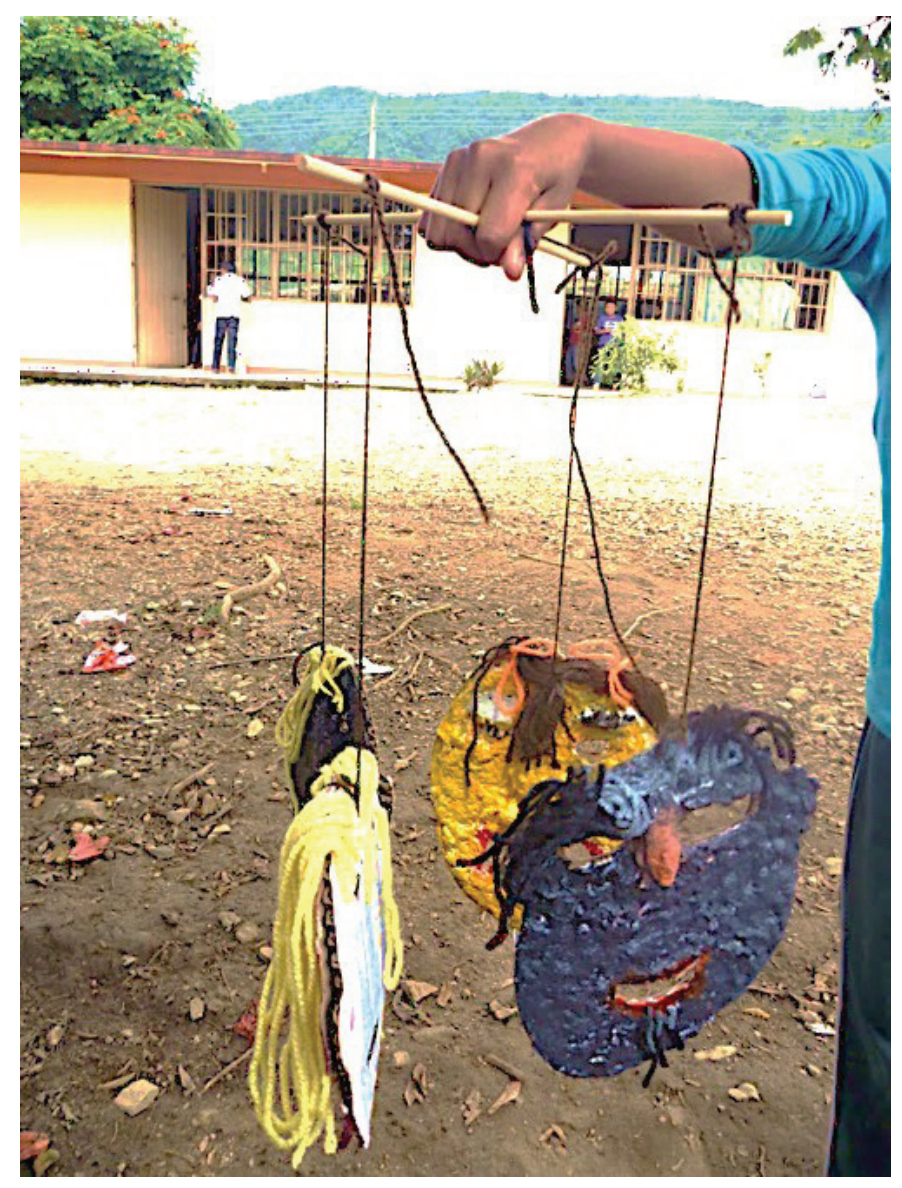

Por su parte, en la montaña de Guerrero, en relación con las representaciones sociales del grupo sobre las diferentes poblacio- 
nes y colores de la piel humana, y sobre si creían que había unos mejores que otros, antes de hacer el ejercicio de las máscaras de los colores humanos, $95.5 \%$ de los alumnos pensaba que era más conveniente tener algún color de piel que otros. Después del ejercicio y ante la misma pregunta, este porcentaje descendió a $77.5 \%$, es decir, que al menos $18 \%$ de ellos tomó conciencia al hacer la actividad de que no hay mejores o peores colores de piel. A la pregunta de si les gustaría tener otro color de piel diferente del que tienen, $95.5 \%$ de los alumnos contestó que sí. Las razones de ello fueron, principalmente, las representaciones sociales de los alumnos, muy relacionadas con los medios masivos de comunicación, que a menudo muestran a quien tiene otro color de piel (diferente de los más comunes en México) como más exitoso en la vida o porque así son en otros países, influidas, en gran parte, por lo que ven en la televisión, de acuerdo con las respuestas que dieron los alumnos en el cuestionario, relacionadas con estos puntos. De entre este porcentaje, 36\%, piensa que en México es mejor tener la piel blanca, seguido por $27 \%$ que cree que es mejor tener la piel amarilla y el más bajo, sólo 1 niño (el 4.5\%) piensa que el cobrizo, correspondiente a los pueblos indígenas, mostrando ya cierto problema de discriminación en sus percepciones, cuando provienen de estos medios de comunicación. Sin embargo, esta información no es concluyente, pues no coincide con otros aspectos observados sobre cómo viven en esta comunidad guerrerense su identidad y su lengua indígena con bastante orgullo.

Por otro lado, en ambos contextos, el cuestionario también mostró que bastante más de la mitad de los alumnos entendió que el color de la piel está determinado por un pigmento llamado melanina, que se genera para proteger a las personas de los diferentes tipos de clima en el mundo y que el origen de todos los seres humanos, hasta donde se conoce, es África. De esta manera, las respuestas demostraron que el ejercicio de las máscaras y el móvil, junto con lo revisado en la parte teórica y lo discutido en clase, los hizo reflexionar sobre los prejuicios, la arbitrariedad y la injusticia que existe en estas maneras de pensar y de ver las cosas, así como sobre su propio origen y el de muchos de sus compañeros. 
El ejercicio de los collages involucró transversalmente las materias de Geografía, con el tema de la población y la diversidad humana, y Formación cívica y ética, con el tema de respeto y aprecio de la diversidad. Se presentó a los alumnos un Power Point con el tema de la diversidad humana en varios de sus aspectos, como pueden ser la diversidad cultural, religiosa, sexual, de capacidades, haciendo un especial hincapié en la diversidad étnica en México y se discutió con el grupo al respecto.

Los collages constaron de dos partes: en la primera se trataba de realizar un collage de una persona con rasgos y características físicas más caucásicos, representantes de zonas europeas o norteamericanas y de acuerdo con lo que se encontraba en cierto tipo de revistas más comerciales y recreativas, y la segunda consistía en hacer un collage de una persona que representara más pluralidad y diversidad, tanto en sus rasgos como en su vestimenta, origen cultural o género con revistas de perfil cultural y científico. Crearían todo ello utilizando las mismas revistas y periódicos nacionales variados y con la indicación de fijarse en cuáles rasgos y fisionomías eran predominantes en estos documentos recreativos e informativos. A lo largo de la realización del ejercicio, aparecieron varias representaciones sociales construidas por el grupo y por la escuela, de acuerdo con lo visto en el marco metodológico, sobre cómo presentan ciertos medios de comunicación, muchas veces los de mayor consumo (que, en este caso, son las revistas más comerciales), a la mujer o al hombre mexicanos promedio, de acuerdo con sus características físicas y que es como aparecen más frecuentemente en estos mismos medios, en este caso revistas y periódicos nacionales de gran distribución, pero que se extiende, por supuesto, a la televisión y a publicidad variada.

Estas representaciones sociales hablan de cómo se perciben a sí mismos los niños indígenas de Chimalhuacán, en relación con lo que consumen en los medios masivos, así como con la idea que elaboran colectivamente sobre la identidad y el ser mexicano a partir de estos medios de comunicación. Para estas representaciones sociales surgidas de muchos de estos medios, como lo mostraron varios de los ejercicios y comentarios de los alumnos, en México predomina- 
ría un tipo de mujer u hombre de tez blanca con vestimenta occidental y de un cierto nivel socioeconómico alto, construcción del imaginario proveniente de estos medios muy lejana de la realidad.

La figura 5a muestra una mujer de piel blanca y rasgos caucásicos realizada por una alumna que explica:

Es una persona blanca porque no encontré una persona indígena o mestiza en las revistas, no había ninguna. Viste un pantalón de cuero, unas zapatillas de piel, un cinturón igual y una sudadera de tipo gamuza y, según esta persona, va de viaje y por eso tiene su maleta.

- Figuras 5a y 5b: Collages sobre la diversidad y la discriminación, Chimalhuacán, Estado de México

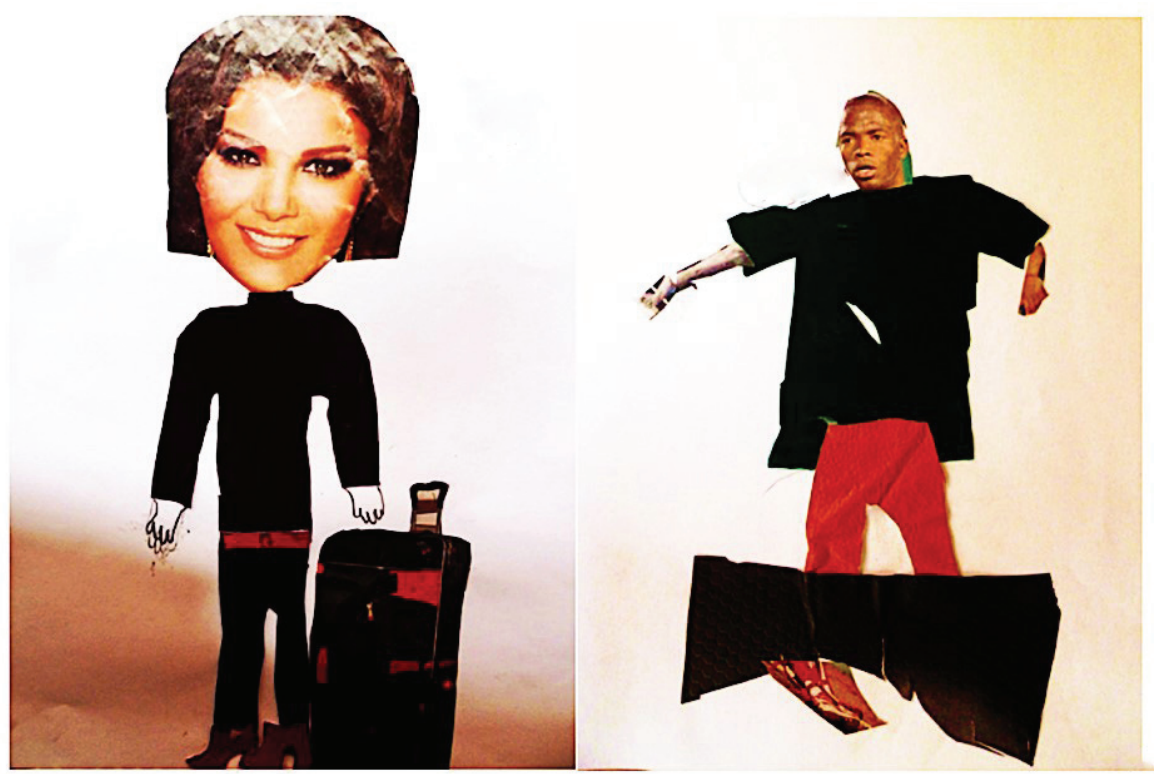

En la figura 5b, el alumno que realizó el collage dijo que a quien él estaba representando era a un indígena y por eso tenía la camisa rota. Se le llamó la atención sobre lo que estaba diciendo, explicándole que cualquiera podía tener rota la camisa y muchas veces los indígenas tenían mucha dignidad en su actuar y en su vestir, además de recordarle su propio origen indígena. El maestro de grupo, en 
la entrevista, triangulando así estos datos, me confirmó estas observaciones e impresiones comentándome que había notado en el ejercicio una fuerte presencia de prejuicios y estereotipos de moda y vestimenta, de color de piel y de clase social, por ejemplo. En su propia experiencia con la discriminación, se les hizo a los alumnos en el cuestionario posterior a la actividad las siguientes preguntas, con estas respuestas:

¿Alguna vez te has sentido discriminado por alguien?:

De 25 alumnos, 8 de ellos (32\%) respondieron que sí. De entre ellos, 3 fueron niñas y 5 niños.

Si es así, ¿por cuál razón?

Las niñas respondieron lo siguiente: "porque algunas veces me dicen morena; porque soy alta y güera; porque estoy un poco gordita; por fea, y por mi nombre."

Los nińos respondieron lo siguiente: "porque estoy gordo o pasado de peso; porque estoy medio morenito; por moreno y un poco lleno; por gordito; por mi piel".

Es, pues, sorprendente y preocupante que, dentro de estas discriminaciones reconocidas, $62.5 \%$ hicieran alusión al color de la piel y $50 \%$ al sobrepeso, demostrando, con estas cifras, lo ya trabajado en la actividad plástica. La suma supera $100 \%$ porque una o varias respuestas combinan ambas características físicas de color de piel y complexión.

Sobre si ellos mismos habían discriminado y el impacto de la actividad en su propia toma de conciencia sobre lo negativo de esta práctica, los resultados del cuestionario arrojaron que más de $80 \%$ han practicado la discriminación de alguna u otra manera cuando alguien presentaba características diferentes de las de la mayoría, sin que estas características afecten a nadie. Sin embargo, también según estas cifras, el ejercicio del collage tuvo un impacto positivo de concientización de valores y ética en $80 \%$ de los alumnos que respondió que hacer la actividad le hizo percatarse que discriminar es malo, lo que resulta bastante alentador. 
En Malinaltepec, Guerrero, este ejercicio fue muy importante también en este contexto, para trabajar la diversidad de todo tipo como de género, étnica, cultural, sexual, religiosa (véase la figura 6). Por otro lado, funcionó muy bien para darse cuenta de la diferencia entre la escuela urbana y multiétnica de Chimalhuacán y la escuela tlapaneca o me phaa de Guerrero, en cuanto a la percepción que tienen sobre su origen.

Figura 6: Collages sobre la diversidad y la discriminación, Chimalhuacán, Malinaltepec, Guerrero
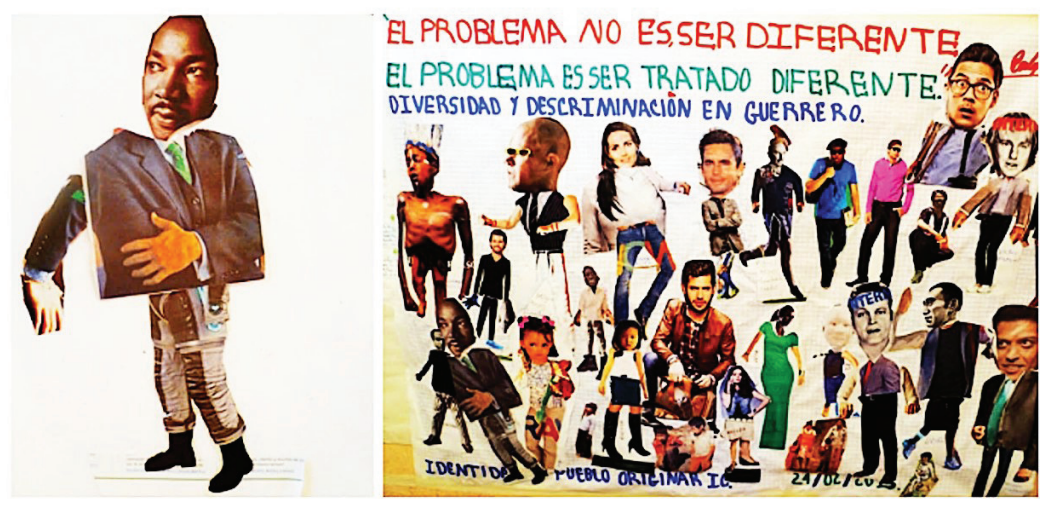

Es muy notorio el contraste de cómo viven la identidad indígena en un contexto y en otro, ya que en la escuela de Guerrero, en general, no se advirtió vergüenza o negación de este origen sino, muy por el contrario, orgullo y dignidad, y sobre todo una gran naturalidad al respecto.

De nuevo, un agente cohesionador muy importante para este reconocimiento y congruencia en relación con el origen étnico e identidad indígena en esta localidad, y seguramente en todo el municipio de Malinaltepec y en los pueblos indígenas de México en general, es la lengua. Ésta da a los pueblos identidad cultural y comunitaria y, por lo tanto, sentido de pertenencia, todos se reconocen e identifican hablando me phaa. Como lo explica y confirma muy bien el maestro de grupo, es una manera de vivir:

Es una manera de identidad, no perdemos la lengua... ahí enriqueciendo nuestra lengua y agregando nuestra propia cultura, como 
queremos dar clase en nuestra lengua, es una manera de vivir, no podemos decir que se acabe, no podemos decir que esto se extermine, al contrario, dar prioridad para que tenga más auge, quizá a nivel estatal, nacional, que sí vivimos como me phaa.

Aun así, 35\% de los niños respondieron en el cuestionario de la actividad que se han sentido discriminados en algún momento de su vida por su color de piel, puede suponerse que son niños que han tenido más contacto con otros contextos o con ciudades y eso influye en ese sentido, según el testimonio de otra maestra de la escuela.

Por otro lado, de acuerdo con el ejercicio de los collages con diferentes tipos de revistas, el primero con revistas y periódicos comerciales y el segundo con otras más culturales y científicas, los hizo reflexionar críticamente, como en la escuela de Chimalhuacán, sobre el tipo físico que predomina en muchos medios de comunicación de nuestro país. Estas fisonomías generalizadas en determinados documentos, no corresponde con la realidad mixta, multiétnica y plural de México, y de alguna manera fomenta el racismo y la discriminación al presentar una mayoría inexistente, que además, por su estilo de vida tipo occidental, globalizado y uniforme, está representado por estos medios de comunicación más comerciales como símbolos de éxito sociocultural y económico. Asimismo, si no se aplica una mirada crítica, puede confundir y generar sentimientos de inseguridad o desvalorizantes en la población que está creciendo y formándose y que no se identifica físicamente con estos estereotipos. Como se puede ver en las siguientes cifras, en el caso de este grupo de la escuela de Guerrero y a partir de lo encontrado en las revistas, 17 de los 23 alumnos de Guerrero (es decir, 74\%) cree que aparece más cierto fenotipo en las revistas porque en México la mayoría de las personas es así, o porque es mejor o más bonito. En cuanto a la conciencia de que existe discriminación entre los seres humanos, incluso entre ellos mismos, y que esto es perjudicial y negativo, los cuestionarios arrojaron que $65 \%$ de los estudiantes, un porcentaje alto, se percató muy bien de ello, con lo encontrado en las revistas y lo hablado y trabajado en el ejercicio, mientras que $35 \%$, poco o nada. De igual manera, $87 \%$ dijo que, de encontrarse a alguien diferente a ella o a él por alguna razón de discapacidad, religión, orien- 
tación sexual, color de piel, enfermedad, entre otros, lo trataría de la misma forma que a otras personas, lo que nos habla, en el marco del reconstruccionismo social y posmoderno del aprendizaje, de una gran lección cívica, ética y humana.

\section{CONCLUSIONES}

Algo que el estudio manifestó en varias de las intervenciones de educación artística-visual fue la relevancia del proceso creador como generador de concientizaciones y sensibilizaciones en los alumnos sobre otros universos referenciales y contextuales, así como acerca de diferentes situaciones y problemáticas de las que, de alguna manera, se pueden hacer responsables y transformar para reconstruirse igual a ellos mismos que a la comunidad y el mundo del cual forman parte (Agirre, 2005). Esto es muy evidente en todos los trabajos, respuestas a cuestionarios y testimonios presentados aquí en que, como se pudo ver en la puesta en uso, además de haber una participación colectiva y colaborativa ya con los compañeros, ya con los familiares que, en sí misma, reforzaba vínculos, se sensibilizó a los niños sobre diferentes realidades de exclusión e injusticia, se discutió con ellos desde enfoques críticos sobre la diversidad y la discriminación, se reconoció y revaloró el origen indígena, la historia familiar y comunitaria y se reflexionó sobre posibles transformaciones y mejoras al mundo que nos rodea.

Se podría decir que, en parte, en esta forma reconstruccionista social de trabajar la educación artística, el proceso es el mensaje y que la enseńanza-aprendizaje del arte se vuelve un medio para propiciar una serie de conocimientos y acontecimientos teórico-prácticos que repercuten en el alumno y la manera que se va relacionar con él mismo, con los otros y con su entorno, como lo plantea en varios puntos de su libro Agirre (2005).

Asimismo, reaparece Dewey (2008) y su distinción entre producto artístico (como un poema, un templo, una pintura, una escultura) y obra de arte, que él concibe como resultado de la interacción entre el producto y el ser humano que vive, experimenta o crea la obra, es decir, el proceso.

Vuelve también Geertz (1994) y su riña de gallos balinesa, que da lugar a todo un sistema y codificaciones simbólicas de interrela- 
ciones sociales y culturales en el seno de la sociedad que la practica. Agirre (2005, p. 331) lo explica muy bien cuando dice acerca del reconstruccionismo algo que se aplica muy adecuadamente a lo surgido en esta investigación: "la pedagogía artística reconstruccionista sostiene que comprender, desde una perspectiva dinámica de la cultura, no es solamente encontrar valores culturales en la obra de arte, sino dar cuenta del sistema de relaciones sociales, políticas, estéticas y culturales que la obra concita".

En el proceso creativo y en la obra artística se pueden dar cita experiencias y vivencias, aprendizajes y reflexiones que, consumados con éxito y más allá del placer estético, modificarían de alguna manera en el terreno de lo simbólico-visual, los acercamientos y relaciones de los sujetos consigo mismos, entre ellos y con su mundo.

La investigación expuso, en relación con el tema del origen indígena, una de las grandes diferencias entre ambas comunidades, pues aparecieron dos tendencias o actitudes bastante opuestas de acuerdo con el lugar donde se hizo el trabajo de campo.

En la escuela primaria indígena urbana de Chimalhuacán, Estado de México, cuya población, en su mayoría, es un mosaico de pueblos originarios, se notó claramente una fuerte inclinación a olvidar e incluso a negar el origen y las lenguas indígenas, ya sea por motivos de discriminación o vergüenza, de adaptación, de deficiencias escolares o del mismo imaginario colectivo considerado mestizo en el que se insertaron al migrar, en el cual este origen y lenguas originarios son a menudo sinónimos de pobreza y fracaso, y pueden percibirse como obstáculos para su desarrollo socioeconómico, integración, progreso social y "modernización", como se vio en algunas representaciones sociales al respecto.

Por su lado, en la escuela indígena rural de la montaña de Guerrero, si bien también existen ciertos prejuicios o estereotipos provenientes, sobre todo, de los pocos medios de comunicación a los que tienen acceso, que no son locales, o de la escasa experiencia migratoria a las ciudades, no se notó gran conflicto en cuanto a la vivencia o aceptación del origen indígena, que está indisolublemente ligado a la lengua, a un estilo de vida comunitario muy arraigado y a la cultura local asumida con orgullo.

Muy a menudo las composiciones visuales, al recuperar y fortalecer la identidad de pueblo originario de donde provienen los 
alumnos y concientizarlos éticamente sobre la discriminación, por ejemplo, en esta lógica posmoderna y de reconstrucción social que mueve a los alumnos en un sentido crítico y transformador, también reflejan esto. Varios ejercicios fueron pensados para reconocer, fortalecer y concientizar estos aspectos en los alumnos, obteniendo diversas experiencias y resultados sumamente provechosos no sólo para ellos, sino para toda la comunidad de aprendizaje.

Las temáticas relacionadas abarcaron desde la migración y su geografía, hasta tradiciones, gastronomías, faunas originarias, la representación de sus parientes y su historia familiar, el estado natal de la familia, todas ellas de nuevo conectadas con las propias vivencias y los conocimientos locales de los alumnos que de esta manera afianzaron lo que ya sabían, a la vez que ampliaron, también de manera visual y conceptual, sus referentes culturales. Estos trabajos generaron pequeños relatos etnográficos y posmodernos (Lyotard, 2006; Rockwell, 2009) que dan voz a los que no la tienen, en representaciones visuales y narraciones orales sobre sus propios universos locales y particulares, que de esta forma cobraban mucha importancia para ellos.

Los ejercicios artístico-visuales implementados desde el enfoque reconstruccionista posmoderno y multicultural contribuyeron de manera muy significativa (sobre todo en el ámbito indígena urbano en que dicha identidad, como ya se dijo, llega a ser rechazada) para reconocer, tomar conciencia y dignificar este origen identitario. En una perspectiva más amplia e intercultural, abarcaron y adoptaron, con pláticas, discusiones y creaciones individuales y en equipo, un punto de vista reflexivo y crítico hacia la discriminación étnica o racismo, en su caso particular, y hacia cualquier tipo de discriminación e intolerancia en general, dirigidas a cualquier minoría, ya sea de tipo físico, étnico, de clase social, religioso, de género, sexual o por minusvalía.

A este respecto, aparecen sumamente pertinentes y clarificadoras las palabras de otra reconstruccionista social y posmoderna experta en educación artística, la brasileña Barbosa (2009, p. 3), cuando dice en su relevante texto Arte, educación y cultura (2009):

Entre las artes, el arte visual, que tiene a la imagen como materia prima, hace posible la visualización de quiénes somos, dónde estamos y cómo nos sentimos. El arte en la educación como expre- 
sión personal y como cultura es un instrumento importante para la identificación cultural y el desarrollo. A través del arte es posible desarrollar la percepción y la imaginación, aprender la realidad del medio ambiente, desarrollar la capacidad crítica, permitiendo analizar la realidad percibida y desarrollar la creatividad de tal manera que mude la realidad que fue analizada. Recordando a Fanon, diría que el arte capacita a un hombre o a una mujer para no ser un extraño en su medio ambiente ni un extranjero en su propio país. El arte supera el estado de despersonalización, insertando al individuo en el lugar al que pertenece.

Es así como contexto y lenguas indígenas van conformando identidades que, en estas dos comunidades urbana y rural, son vividas y asumidas de forma muy diferente, y que en ambos casos y a través de la educación artística reconstruccionista aplicada a lo largo de la investigación, se manifestaron, fortalecieron y concientizaron de forma muy notoria y positiva.

\section{REFERENCIAS BIBLIOGRÁFICAS}

Agirre, I. (2005). Teorías y prácticas de la educación artística. Barcelona, España: Octaedro-EUB.

Barbosa, A. M. (2009). Arte, educación y cultura. Recuperado de https://es.scribd. com/doc/23417505/Arte-Educacion-y-Cultura-Ana-Mae-Barbosa

Beltrán, J. A., Bermejo, V., Pérez, L. F., Prieto, M. D., Vence, D., y González, R. (2000). Intervención psicopedagógica y currículum escolar. Madrid, España: Pirámide.

Benavides, M. O., y Gómez-Restrepo, C. (2005). Métodos en investigación cualitativa: triangulación. Revista Colombiana de Psiquiatría, 34(1), 118124. Recuperado de http://www.scielo.org.co/scielo.php?script=sci_art text\&pid=S003474502005000100008\&lng=en\&tlng=es

Clifford, J. (2001). El dilema de la cultura. Antropología, literatura y arte en la perspectiva posmoderna. Barcelona, España: Gedisa.

Corenstein, M. (2001) Un repaso de la etnografía educativa en México hoy (En línea). Educación Física y Ciencia, 5, 55-67. Recuperado de http:// www.memoria.fahce.unlp.edu.ar/art_revistas/pr.92/pr.92.pdf.

Denzin, N. K. (2015). Manual de la investigación cualitativa. Vol. IV. Buenos Aires, Argentina: Gedisa.

Dewey, J. (2008). El arte como experiencia. Barcelona, España: Paidós Estética. 
Eisner, E. (2004). El arte y la creación de la mente. Barcelona, España: Paidós. Efland, A. (2002). Una historia de la educación del arte. Barcelona, España: Paidós Arte y educación.

Efland, A. D., Freedman, K., y Stuhr, P. (2003). La educación en el arte posmoderno. Barcelona, España: Paidós.

Freire, P. (2002). Pedagogía del oprimido. México: Siglo XXI Editores.

Geertz, C. (1994). Conocimiento local. Ensayos sobre la interpretación de las culturas. Barcelona, España: Paidós Básica.

Giroux, H. (1995). La pedagogía de frontera en la era del posmodernismo. En A. De Alba (Comp.), Posmodernidad y educación. México: Miguel Ángel Porrúa.

Lyotard, J. F. (2006). La condición postmoderna. Madrid, España: Cátedra. Moreno, M. G. (2016). El archivo del estudio del racismo en México. Desacatos, (51), 92-107. Recuperado de http://www.scielo.org.mx/scielo.php?script=sci_ arttext\&pid=S1607050X2016000200092\&lng=es\&tlng=es

Moscovici, S. (1979). El psicoanálisis, su imagen y su público. Buenos Aires: Huemul.

Murueta, M. E. (2004). Alternativas metodológicas para la investigación educativa. México: Amapsi.

Rockwell, E. (2009). La experiencia etnográfica. Historia y cultura en los procesos educativos. Buenos Aires, Argentina: Paidós.

Sánchez, R. (2008). La observación participante como escenario y configuración de la diversidad de significados. En M. L. Tarrés (Coord.), Observar, escuchar y comprender (pp. 93-126). México: Flacso/El Colegio de México/Porrúa.

SEP (2011). Libro de texto de lengua indígena. México: SEP.

SEP (2010). Programas de estudio 2009, Quinto Grado, Educación básica, Primaria. México: SEP

Schmelkes, S. (2009). Equidad, diversidad, interculturalidad: las rupturas necesarias. En Á. Marchesi, J. C. Tedesco y C. Coll (Coords.), Calidad, equidad y reformas en la enseñanza (pp. 47-56). Madrid, España: OEI, Fundación Santillana.

Vázquez, R., y Zazueta, J. A. (2004). Representaciones sociales: una manera de investigar la realidad escolar. En M. E. Murueta (Coord.), Alternativas metodológicas para la investigación educativa (pp. 85-105). México: Amapsi.

Villanueva, O. E. (2005). Enfoque biográfico y etnográfico en profesores principiantes. En P. Medina (Coord.), Voces emergentes de la docencia. Horizontes, trayectorias y formación profesional (pp. 59-72). México: UPN/Porrúa. 